\title{
Proteomics-based investigation in C2C12 myoblast differentiation
}

\author{
L. Casadei, ${ }^{1}$ L. Vallorani, ${ }^{1}$ A.M. Gioacchini, ${ }^{1}$ M. Guescini,, ${ }^{1}$ S. Burattini, ${ }^{2}$ A. D'Emilio, ${ }^{2}$ L. Biagiotti, ${ }^{2}$ \\ E. Falcieri, ${ }^{2,3}$ V. Stocchi ${ }^{1}$ \\ ${ }^{1}$ Dipartimento di Scienze Biomolecolari, Università degli Studi di Urbino "Carlo Bo", Urbino; 2DISUAN, \\ Università degli Studi di Urbino “Carlo Bo", Urbino; ${ }^{3} \mathrm{GM}$, CNR, Istituti Ortopedici Rizzoli, Bologna, Italy
}

(C2009 European Journal of Histochemistry

Skeletal muscle cell differentiation is a multistage process extensively studied over the years. Even if great improvements have been achieved in defining biological process underlying myogenesis, many molecular mechanisms need still to be clarified.

To further highlight this process, we studied cells at undifferentiated, intermediate and highly differentiated stages, and we analyzed, for each condition, morphological and proteomic changes. We also identified the proteins that showed statistical significant changes by a ESI-Q-TOF mass spectrometer. This work provides further evidence of the involvement of particular proteins in skeletal muscle development. Furthermore, the high level of expression of many heat shock proteins, suggests a relationship between differentiation and cellular stress. Intriguingly, the discovery of myogenesis-correlated proteins, known to play a role in apoptosis, suggests a link between differentiation and this type of cell death.

Key words: C2C12 cells, differentiation, proteome, TEM, 2-D electrophoresis, mass spectrometry.

Correspondence: Luciana Vallorani,

Dipartimento di Scienze Biomolecolari, Università degli Studi di Urbino "Carlo Bo" via I Maggetti 26 Urbino, Italy.

Tel.: +39.0722.303419.

Fax: +39.0722 .303401$

E-mail: luciana.vallorani@uniurb.it

LC and LV contributed equally to this work.

Paper accepted on September 2, 2009

European Journal of Histochemistry 2009; vol. 53 issue 4 (October-December): 261-268
S keletal muscle differentiation is a highly coordinated process, accompanied by deep changes in both cell morphology and gene expression patterns. In early myogenesis, specific transcription factors determine the commitment of mesodermal cells to myogenic progenitors and, then, myoblasts. Later, myoblasts exit from cell cycle and differentiate, becoming multinucleated myotubes (Muntoni et al., 2002). However, a number of myoblasts persist in adult muscle as satellite cells, localised between basement membrane and muscle fiber sarcolemma (Cooper et al., 1999). Although they are quiescent in adult muscle, satellite cells are responsible for muscle regeneration following denervation, physical exercise stress or muscle lesions. After damage, they migrate to the injured site and proliferate, fusing to pre-existing fibers or together, to form new myofibers (Hawke and Garry, 2001).

Molecular characterization of proteome is necessary for a complete understanding of biological systems (Giorgianni et al., 2003) and previous studies have been also performed on gene expression profile during in vitro differentiation of C2C12 myoblast cell line (Delgado et al., 2003; Tomczak et al., 2004). A proteomic approach to myoblast differentiation was used by Tannu et al. (2004), who compared proteins in proliferating C2C12 cells and fully differentiated myotubes but not along myogenic differentiation. Also Kislinger et al. (2005) report an extensive LC-MS based shotgun profiling analysis of protein expression changes in differentiating $\mathrm{C} 2 \mathrm{C} 12$ myoblasts.

Here we describe protein expression changes (by 2D-PAGE), correlated to morphological ones (transmission electron and confocal microscopy), at the undifferentiated condition (T0), like as 0 in T0 intermediate (T3-T5) and high (T7) stages of differentiation. We also identify, by electrospray 
ionisation (ESI) (Griffiths et al., 2001) tandem mass spectrometry, the proteins for each stage that show the major expression changes.

\section{Materials and Methods}

\section{Cell cultures}

C2C12 mouse adherent myoblasts were grown as described (Curci et al., 2008). To induce myogenic differentiation, when about $80 \%$ cell confluence was attained, the medium containing $10 \%$ fetal calf serum was changed with a $1 \%$ new one. Cells have been observed at the undifferentiated stage and at 3, 5, 7 days of differentiation with a Nikon Eclipse TE 2000-S reverted microscope (RM) and photographed with a digital DN 100 Nikon system.

\section{Transmission electron microscopy}

Cells, growing in flasks, were fixed with $2.5 \%$ glutaraldehyde in $0.1 \mathrm{M}$ phosphate buffer for 15 min, gently scraped and centrifuged at $520 \mathrm{~g}$. Pellets were furtherly processed as reported (Burattini et al., 2004).

\section{Immunofluorescence}

Immunofluorescence (IF) was carried out in dishes containing cover slides, where cells had been seeded and cultured. Monolayers were fixed with $4 \%$ paraformaldehyde in PBS for 30 min, washed and permeabilized with $0.2 \%$ Triton $X$ 100 in PBS for 10 min. For actin labelling, cells were treated with $5 \%$ normal horse serum (D.B.A.) and $2 \%$ bovine serum albumin (Sigma) in PBS for 30 min and then incubated with a mouse antibody againstsarcomeric actin (1:100 in PBS, Sigma) overnight at $4^{\circ} \mathrm{C}$. After rinsing, the monolayers were incubated with a FITC-conjugated horse anti-mouse secondary antibody (1:50 in PBS, D.B.A., Vector) for 75 min. Nuclei were counterstained with DAPI $(1: 20000$ in PBS, Sigma) for 5 min. Cells were mounted with an antifading medium and analyzed by means a Zeiss LSM 510 Meta confocal microscope.

\section{Sample preparation for two-dimensional electrophoresis}

Cells were detached from flasks by means of $0.25 \%$ trypsin for $10 \mathrm{~min}$ at $37^{\circ} \mathrm{C}$, and washed with 0.1 M PBS, pH 7.4 added with a tablet of protease inhibitor cocktail (Roche diagnostic
Bmbh, Germany). After centrifugation at $1300 \mathrm{~g}$, supernatant was removed and pellet was resuspended in $8 \mathrm{M}$ urea, 4\% CHAPS, $65 \mathrm{mM}$ DTE, $40 \mathrm{mM}$ Tris base and sonicated for $5 \mathrm{~s}$ on ice. After centrifugation at $21000 \mathrm{~g}$, protein concentration was determined by Bradford assay (Bradford, 1976).

\section{Two-dimensional electrophoresis}

Forty-five $\mu \mathrm{g}$ (analytical runs) or $500 \mu \mathrm{g}$ (semipreparative runs) of total protein was used for each electrophoretic run. Two-dimensional electrophoresis (2-DE) was carried out as previously described (Sestili et al., 2009). Briefly, isoelectric focusing was made on Immobiline strips providing a non linear $\mathrm{pH}$ 3-10 gradient (Amhersham Biosciences) using a Multiphor II system (Amhersham Biosciences). After IPG strip equilibration, the second dimension was carried out in a Laemmli system on 9-16\% polyacrylamide linear gradient gels $(18 \mathrm{~cm} \times 20 \mathrm{~cm} \times 1.5 \mathrm{~mm})$ at 40 $\mathrm{mA} / \mathrm{gel}$ constant current, until the dye front reached gel bottom.

\section{Protein visualization and image analysis}

Analitical gels were stained with ammoniacal silver nitrate (Oakley et al., 1980). Semi-preparative gels for mass spectrometry analysis were stained with Brilliant Blue G-Colloidal (SigmaAldrich, Saint Louis, USA) according to the manufacturer's procedure. Stained gels were scanned with a Scan-jet 4c (HP, Palo Alto, CA, USA) and the data were analysed with Melanie 3 computer software. Protein quantification values are calculated as relative volume ( $\%$ Vol). Gel calibration was carried out using human plasma as internal standard (Bini et al., 1996). To take into account experimental variation, 2-D gels were normalized by each value spot volume data by the total volume of all the matched spots in the 2-D gel image to obtain a normalized spot volume value. To test the significant differences in the relative protein levels for each spot, a paired Student's t-test statistic was applied at a significant level of $p<0.05$.

\section{In-gel digestion}

Protein spots extracted from 2-D gels were rinsed with $100 \mathrm{mM}$ ammonium bicarbonate and then dehydrated with acetonitrile. Reduction, alkylation and tryptic digestion were carried out according to the literature (Shevchenko et al., 1996). 


\section{Mass spectrometry}

LC-ESI-MS/MS analysis was performed using a Q-TOF micro ${ }^{\mathrm{TM}}$ mass spectrometer (Micromass, Manchester, UK) equipped with a Z-spray nanoflow electrospray ion source and a CapLC system. The sample was analyzed using a Symmetry C18 nano column (Waters, Milford, MA, USA) as an analytical column.

For protein identification, MS/MS spectra were searched by MASCOT (Matrix science, www.matrixscience.com, U.K.) using database of NCBI nr. For unmatched peptides, however, good quality MS/ MS spectra were manually sequenced using de novo sequencing process (carried out by PepSeq of the Masslynx 4.0 software, Micromass), and the obtained sequence was subsequently used in Expasy TagIdent.

\section{Results}

When switched to differentiation medium, mitotic $\mathrm{C} 2 \mathrm{C} 12$ myoblasts rapidly stop proliferating and initiate the differentiation program. The cells exhibit striking morphological changes along 0-10 days, finally fusing into mature multinucleated myotubes.

Figure 1 evidences some peculiarities appearing at TEM and/or confocal microscope observations, during $\mathrm{C} 2 \mathrm{C} 12$ differentiation, which can be correlated, in our opinion, to proteome changes. Cell membrane contact areas are frequently present at early stage (Figure $1 \mathrm{~A}$ ) while focal cell fusions (Figure 1B) can be revealed at intermediate differentiation stage. In this condition stress fibers are clearly identifiable, at TEM, as peripheral aggregations of filaments (Figure $1 \mathrm{C}$ ) and, at confocal microscopy, by $\alpha$-sarcomeric actin containing definite patches (Figure 1D). At late differentiation stage, occasional apoptotic cells appear: an apoptotic nucleus, with mostly condensed chromatin, is shown in Figure $1 \mathrm{E}$. A large number of mitochondria also characterizes late $\mathrm{C} 2 \mathrm{C} 12$ differentiation, as evidenced in $\mathrm{IF}$ myotube.

In order to have a picture of the protein actually expressed during the different phases of differentiation, we performed a 2D-PAGE over a 10-day time span on differentiating $\mathrm{C} 2 \mathrm{C} 12$ myoblasts.

Computer analysis of the different gels $(n=4$ replicates), obtained from $2-D E$ analysis, revealed significant changes in 26 spots, shown in Figure 2.
The level of expression of many proteins appeared to increase in a linear way if compared to the differentiation grade, reaching higher values at T5 and T7: the average number of proteins in undifferentiated cells is in fact 934, at T3 1129; at T5 1252 and at T7 it is 1290 .

Twenty-six spots were identified by ESI-Q-TOF

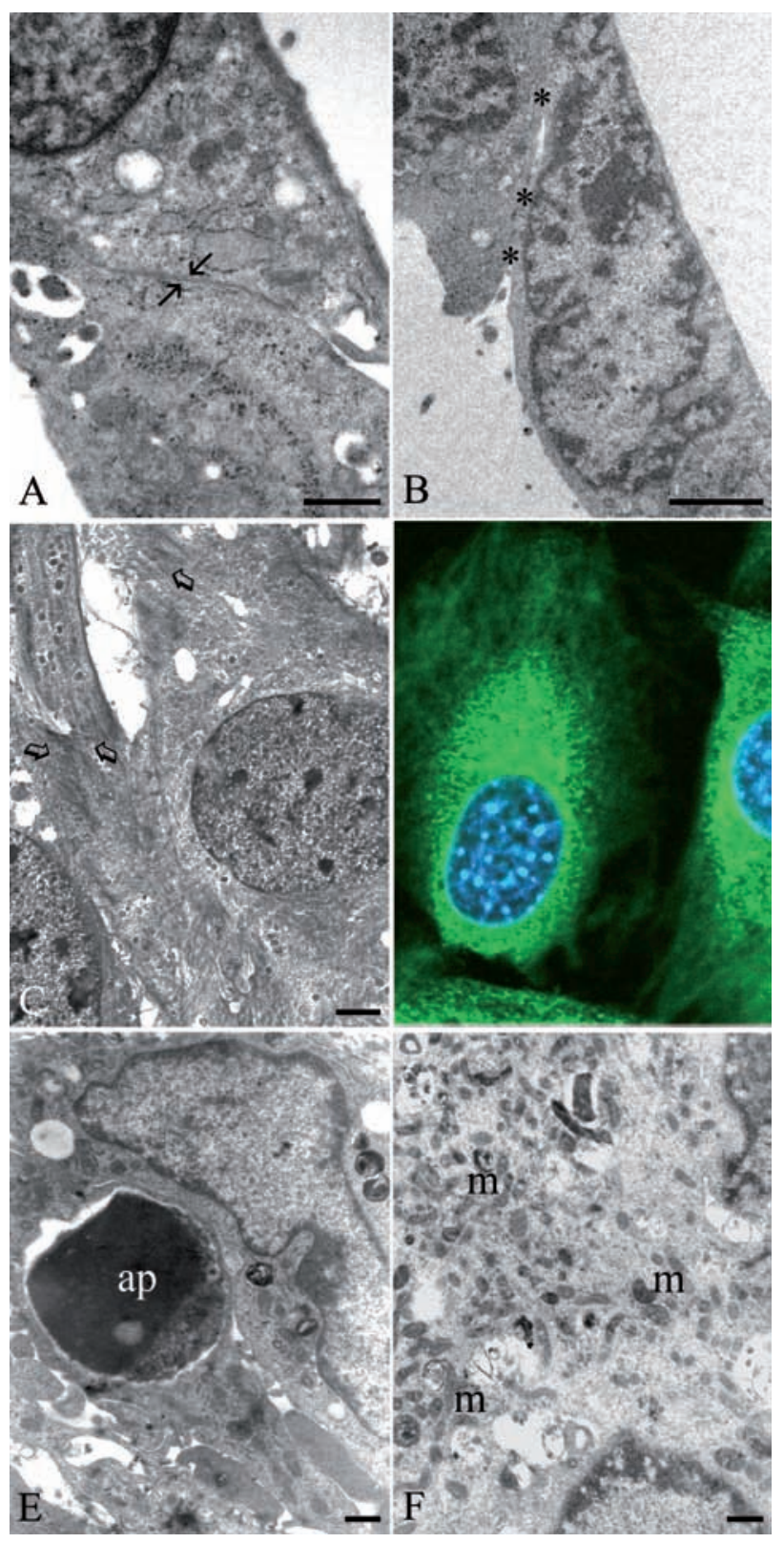

Figure 1. C2C12 differentiation peculiarities, identified by TEM (A,B,C,E,F) and confocal microscope IF (D) at early (A), intermediate (B,C,D) and late (E,F) time. Cell membrane contacts $(\rightarrow)$ are followed by the fusion of focal membrane areas $\left(^{*}\right) . \alpha$ Sarcomeric actin can also be identified as stress fibers, well recognizable at TEM $(\Rightarrow)$, and as strongly fluorescent cytoplasmic spots at IF (D), at the intermediate stage. Late differentiation is characterized by the appearance of apoptotic cells (ap) and by the significantly increased number of mitochondria ( $m$ ). $\mathrm{A}-\mathrm{F}$, bar $=1 \mu \mathrm{m}$ 
MS. The application of tandem mass spectrometry $\left(\mathrm{MS}^{n}\right)$ to peptide-derived ions using hybrid quadrupole-TOF instruments, provides both sequence and structural information, which increases the confidence in protein identification, since a single peptide sequence may be sufficient to identify a protein. Proteins and their quantitative changes are listed in Table 1. Their potential involvement in the myoblastic differentiation stage will be reported in the discussion.

\section{Discussion}

\section{Undifferentiated stage}

The presence of high quantity of vimentin during the starting phase of differentiation and its decrease during development progression confirm the phase-specific role of this protein. Runembert et al. (2002) reported that vimentin does not affect cell proliferation and differentiation directly, but participates in preserving proper transport functions, possibly by maintaining membrane physical state.

Stathmin expression is important in cell proliferation. Cell-cell contacts (Figure $1 \mathrm{~A}$ ), probably mediated by adhesion molecules such as cadherins, are responsible for the high densityinduced expression of stathmin, which might then be involved in the control of myoblast proliferation (Balogh et al., 1996). In our case stathmin expression is higher during the starting phase (cell proliferation), and decreases during cell differentiation.

Gelsolin-like capping protein plays a role in organizing actin filaments during sarcomere formation. Hug et al. (1995) monitored its levels in Dictyostelium cells and found changes in resting and chemoattractant-induced actin assembly, consistent with the in vitro properties of capping protein. Cell movement is activated with capping protein increase and decreased with their down regulation. So capG overexpression in our model may

Table 1. Identification of proteins differentially expressed during myoblast differentiation.

\begin{tabular}{|c|c|c|c|c|c|c|c|}
\hline Spot (ID) & Protein & $\begin{array}{l}\text { Time } \\
\text { (high } \\
\text { expression) }\end{array}$ & Score & $\begin{array}{l}\text { Sequenze } \\
\text { coverage (\%) } \\
\text { /no. of peptides } \\
\text { matched }\end{array}$ & NCBI ID & pl & $\begin{array}{l}\text { Nominal } \\
\text { mass }\end{array}$ \\
\hline 342 & Vimentin & $\mathrm{T}_{0}$ & 1654 & $62 / 27$ & Vime-mouse & 5.06 & 53524 \\
\hline 1065 & Stathmin & $\mathrm{T}_{0}$ & 253 & $29 / 4$ & STMN1_mouse & 5.77 & 17133 \\
\hline 721 & Acidic ribosomal phosphoprotein P0 & $\mathrm{T}_{0}$ & 61 & $3 / 1$ & Q5FWB6_mouse & 5.91 & 34165 \\
\hline 1173 & 10 kDa heat shock protein, mitochondrial (Hsp10) & $\mathrm{T}_{0}$ & 277 & $53 / 6$ & CH10_MOUSE & 8.18 & 10825 \\
\hline 723 & Capping protein & $\mathrm{T}_{0}$ & 470 & $26 / 8$ & Q99LB4_mouse & 6.47 & 38745 \\
\hline 282 & Carteticulin & $\mathrm{T}_{0}$ & 230 & $12 / 6$ & Q3TVD2_MOUSE & 4.34 & 47992 \\
\hline 920 & Rho GDP-dissociation inhibitor 1 & $\mathrm{~T}_{0}$ & 258 & $28 / 5$ & GDIR_MOUSE & 5.12 & 23262 \\
\hline 541 & Actin alpha, skeletal muscle & $\mathrm{T}_{3}-\mathrm{T}_{5}$ & 246 & $10 / 3$ & A24904 & 5.23 & 42024 \\
\hline 329 & IMP dehydrogenase & $\mathrm{T}_{3}-\mathrm{T}_{5}$ & 198 & $6 / 3$ & JT0565 & 6.84 & 55750 \\
\hline 175 & Heat shock 70 kDa protein 5 (grp78) & $\mathrm{T}_{3}-\mathrm{T}_{5}$ & 328 & $9 / 4$ & Q9DC41 & 5.01 & 72378 \\
\hline 89 & Endoplasmin precursor (Hsp90kDa beta member 1) & $\mathrm{T}_{3}-\mathrm{T}_{5}$ & 110 & $2 / 1$ & A29317 & 4.74 & 92418 \\
\hline 1106 & Superoxide dismutase & $\mathrm{T}_{3}-\mathrm{T}_{5}$ & 277 & $32 / 4$ & SODC_MOUSE & 6.03 & 15802 \\
\hline 1040 & Interferon-activable protein (p205) & $\mathrm{T}_{3}-\mathrm{T}_{5}$ & 7 & $14 / 1$ & Q8C4X3_mouse & 5.17 & 16510 \\
\hline 736 & Docking protein 4 & $\mathrm{~T}_{3}-\mathrm{T}_{5}$ & 10 & $3 / 1$ & BAC27829 & 8.18 & 37017 \\
\hline 205 & Heat shock protein, 70 KDa 8 & $\mathrm{~T}_{3}-\mathrm{T}_{5}$ & 827 & $31 / 15$ & Q6NZD0_MOUSE & 5.28 & 70828 \\
\hline 727 & Annexin I & $\mathrm{T}_{3}-\mathrm{T}_{5}$ & 607 & $32 / 9$ & LUMS1 & 6.97 & 38710 \\
\hline 1072 & 4733401II05 Rik protein & $\mathrm{T}_{3}-\mathrm{T}_{5}$ & 114 & $8 / 1$ & Q9D643 & 6.96 & 13237 \\
\hline 64 & Gelsolin cytosolic & $\mathrm{T}_{7}$ & 141 & $1 / 1$ & A32621 & 5.53 & 80827 \\
\hline 65 & Gelsolin cytosolic & $\mathrm{T}_{7}$ & 141 & $1 / 1$ & A32621 & 5.53 & 80827 \\
\hline 1007 & ATP synthase D chain, mithochondrial & $\mathrm{T}_{7}$ & 237 & $24 / 4$ & ATPD_MOUSE & 5.52 & 18607 \\
\hline 748 & Annexin A5 & $\mathrm{T}_{7}$ & 159 & $4 / 1$ & Q99LA1 & 4.83 & 35716 \\
\hline 740 & Glyceraldehyde-3-phosphate dehydrogenase & $\mathrm{T}_{7}$ & 189 & $21 / 5$ & DEMSG & 8.44 & 35787 \\
\hline 707 & Alcohol dehydrogenase & $\mathrm{T}_{7}$ & 361 & $32 / 9$ & AK1A1_MOUSE & 6.87 & 36433 \\
\hline 860 & Glucocorticoid modulatory element binding protein 1 (GMEB1) & $\mathrm{T}_{7}$ & 9 & $3 / 1$ & Q80Y88 & 4.73 & 61020 \\
\hline 321 & Choline transport-like protein 3 (CTL3) & $\mathrm{T}_{7}$ & 30 & $1 / 1$ & Q921V7 & 7.70 & 67259 \\
\hline 893 & Hypothetical protein & $\mathrm{T}_{7}$ & 54 & $8 / 1$ & Q9D643 & 6.96 & 13237 \\
\hline
\end{tabular}


pH 3
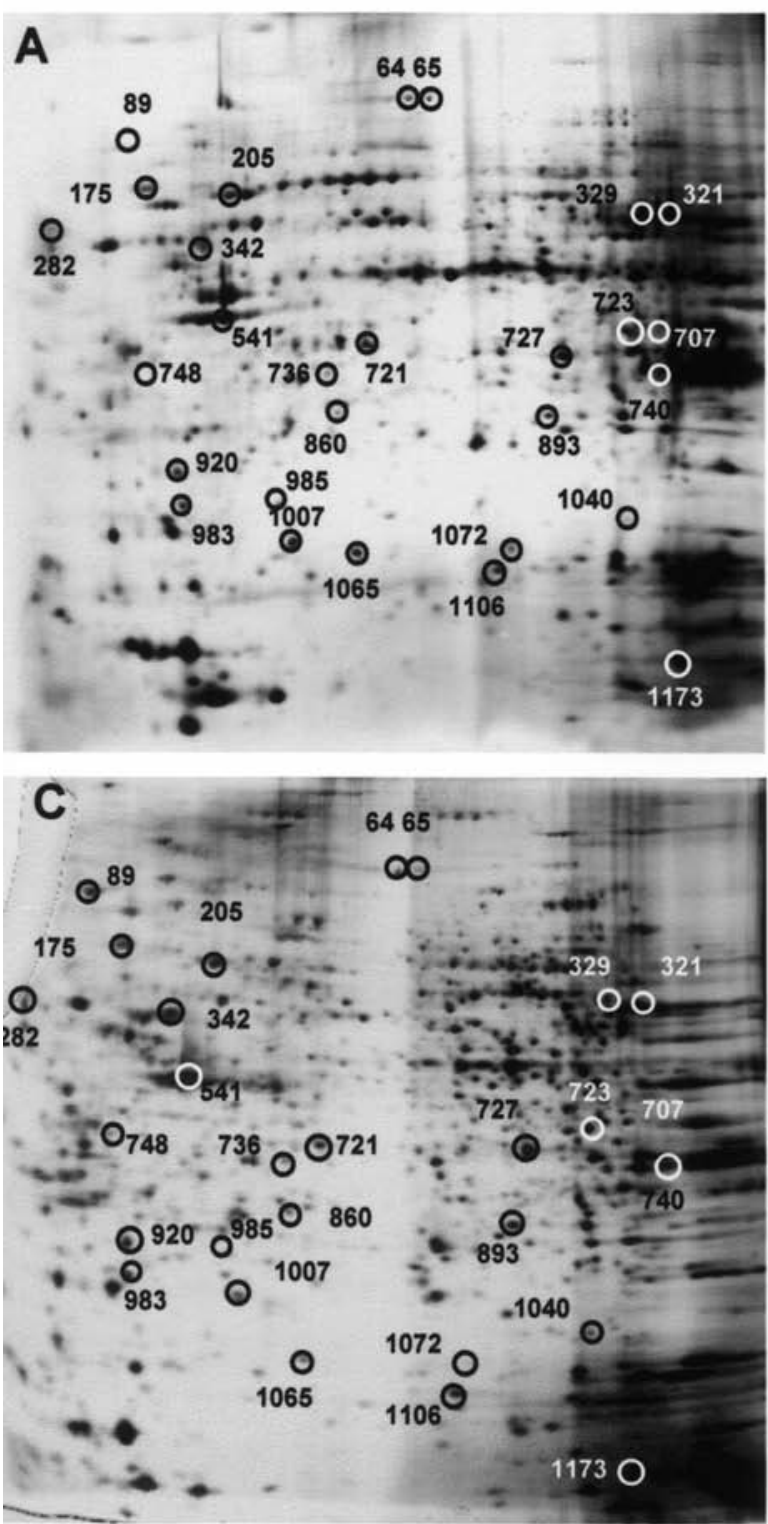

pH 10

pH 3

pH 10

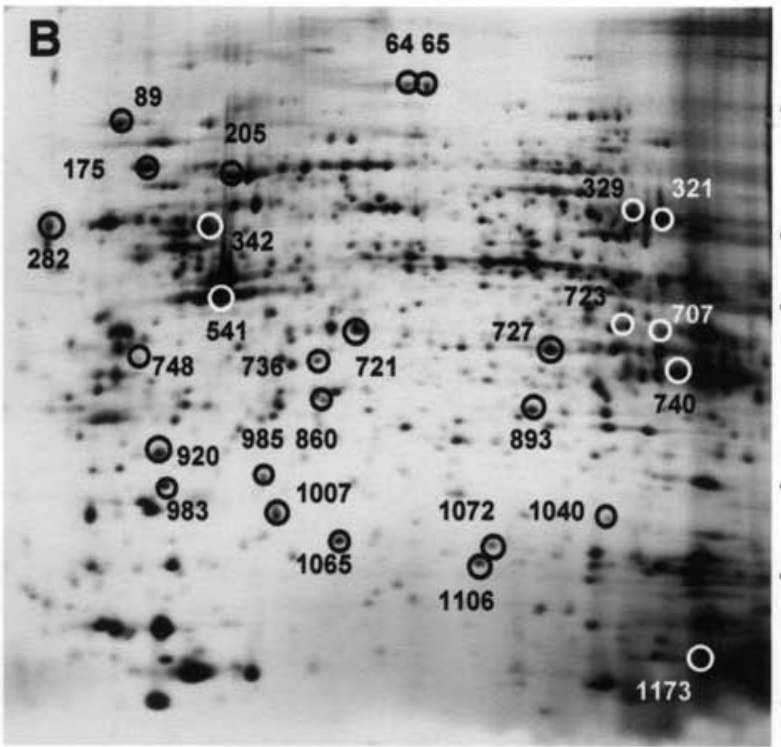

$\mathrm{kDa}$

$-98.1$

$-56.6$

$-43.6$

$-23.9$

$-14.5$

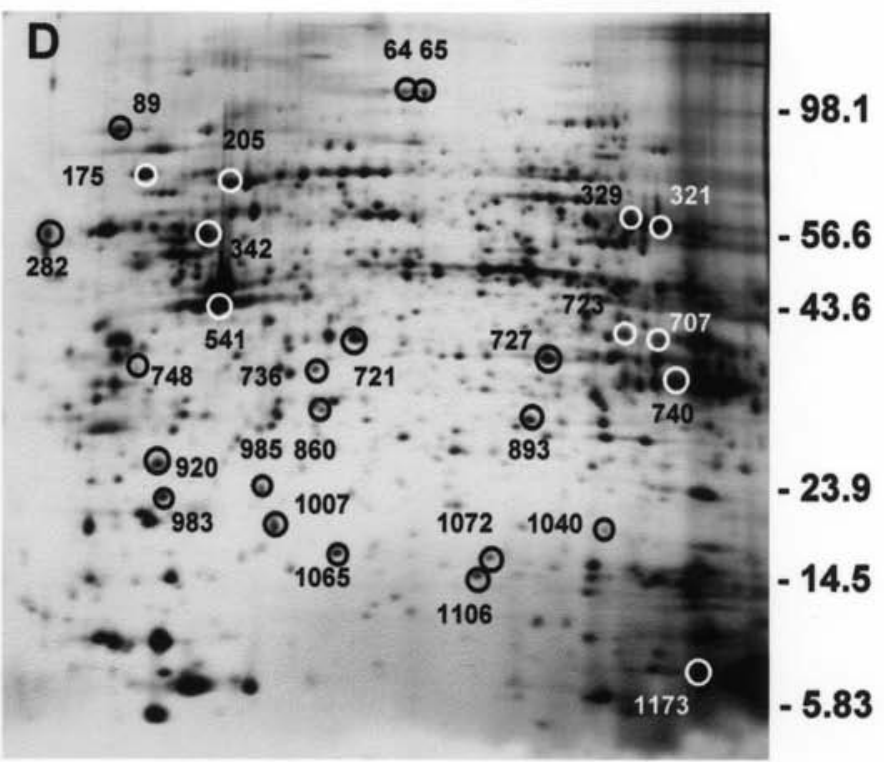

Figure 2. 2-DE of $45 \mu \mathrm{g}$ of C2C12 myoblast during differentiation. (A) Undifferentiated stage (time 0); (B) Early intermediate differentiation stage ( 3 days); (C) Late intermediate differentiation stage ( 5 days); (D) High differentiation phase ( 7 days). Gels were stained with silver nitrate.

be correlated to cell motility requirement.

Acidic ribosomal protein ( $\mathrm{PO}$ ) is a neutral protein, related to acidic ribosomal phosphoproteins P1 and P2 family (Rich and Steitz, 1987). Zaho et al. (2003) found a decrease of P0 during skeletal muscle development by analyzing gene expression changes, by microarray. The early increased expression of P0 could so confirm its specific role in cell proliferation.
Rho family protein role in muscle differentiation was shown in $\mathrm{C} 2 \mathrm{C} 12$, in which it regulates myogenin and MEF2 gene expression (Charrasse et al., 2006). Proliferating myoblasts show high levels of RhoA which are markedly lower in differentiating cells (Iwasaki et al., 2008). Here we report an high expression of rho GDP-dissociation inhibitor 1 during early differentiation, when a proliferative state must be maintained. 
Mitochondria contain several members of the major chaperone families, crucial for maintaining mitochondrial function: hsplo is a eukaryotic cpn10 homologue and, therefore, together with cpn60 is essential for mitochondrial protein biogenesis (Hartman et al., 1992).

\section{Intermediate differentiation stage}

Interferon activable protein (p205) is involved in both lymphoid and myeloid differentiation (Asefa et al., 2006). Our results suggest that p205 is involved in withdrawal from the cell cycle. Major expression level of p205, can be correlated with cell proliferation arrest and cell differentiation start. In fact, we found a high p205 expression at the intermediate differentiation stage.

During myoblast differentiation, hsp90 balances the phosphorylation state of akt by modulating its dephosphorylation by PP2Ac. Akt is an hsp90dependent serine-threonine kinase that plays critical role in muscle differentiation too (Yun and Matts, 2005). In this work we found a major espression of hsp90 in the central phase of differentiation.

Glucose-regulated proteins (GRPs) are localized in the endoplasmic reticulum (ER) (Hirano et al., 1995) and up-regulated in response to $E R$ stress. Our findings suggest a role for GRPs correlated to myoblast differentiation.

Hsp70 is involved not only in protein folding, but also in differentiation and cell-cycle progression. Lee et al. (1998) suggested that it may inhibit the differentiation of early stage $T$ cells. Furthermore, expression of Hspa 8 was markedly down-regulated upon differentiation also in human embryonic stem cells (Son et al., 2005).

Annexin I ( $A 1)$ is one of the 20 known members of the annexin family of calcium and phospholipidbinding proteins. It is known mainly for its ability to promote aggregation and fusion of phospholipid vesicles (Blackwood and Ernst, 1990). So the major expression level of $A l$ in intermediate differentiation stage could be correlated to the myoblast fusion process (Figure 1B). We show that docking protein 4 (dok4) is involved in skeletal muscle development; in particular, its major expression is linked to differentiation. Furthermore, dok4 plays a positive role in activation of the MAP kinase pathway (Grimm et al., 2001), confirming the presence of common pathways between apoptosis and differentiation
(Figure $1 \mathrm{E}$ ) and in agreement with $\mathrm{Al}$ increase. In both cases it brings, indeed, to an increase of MAPK. $\alpha$-Actin is associated to contractile function and this explains the finding of a strong actin expression at intermediate differentiation stage (Figure $1 \mathrm{C}, \mathrm{D}$ ).

Concerning the increment of superoxide dismutase expression, we suppose that it is reliable to regulation of antioxidant defenses in response to cellular differentiation (Franco et al., 1999).

\section{High differentiation stage}

We found a high level of expression for annexin $A 5$ in the final stage of differentiation. The literature reports that $A 5$ is located in myotubes, where it has been described to appear around day 8 of embryonic development, possibly implicated in fusion process (Arcuri et al., 2002).

Gelsolin is best known for its involvement in actin cytoskeleton dynamics. Its role in myogenesis was reported by Scholz and Hinssen (1995), who show that gelsolin increased steadily from the myoblast to terminally differentiated myotubes and hypothesize a functional role of gelsolin in myofibrillar assembly.

ATP synthase is a known mitochondrial enzyme, needed for mitochondrial oxidative phosphorylation. The increase of one of its components during the final phase can be due to the increase of ATP requirement in mature myotube, which progressively acquires contractile capacity, as well as mitochondrial functionality (Figure $1 \mathrm{~F}$ ).

GMEBs were originally examined for their role in modulating the properties of glucocorticoid receptor-mediated transactivation. Members of the muscle-specific RING finger proteins (MURF1,2 , and 3) act as cytoskeletal adaptors and signalling molecules by associating with myofibril components, microtubules and/or nuclear factors. GMEBI may be involved in myofibril signal pathway and muscle gene expression, in agreement with its identification during late myogenesis, when the expression of muscle specific genes is induced.

To conclude, during early differentiation we find proteins able to stimulate myoblast proliferation and to inhibit their differentiation, proteins involved in the maintenance of cellular and nuclear shape, as well as in cell motility, migration and actin filament organization.

At the intermediate differentiation stage, our 
study reveals proteins capable of inducing cell cycle arrest and promoting maturation, thus allowing progenitor cells to differentiate. Furthermore, in this stage myoblasts start fusing into multinucleated myotubes. Annexin 1, could be one of the proteins responsible for this event. We also found that dock 4 plays a positive role in the activation of the MAP kinase, essential for myogenesis (Keren et al., 2006) and probably involved in this particular stage of differentiation program.

At this stage we also identified an increased expression of $\alpha$-actin, involved in the progression of contractile activity.

The main proteins which can be detected in fully differentiated syncytia are: annexin A5, CTL3, gelsolin and ATP synthase, potentially correlated to myotube formation (annexin 5), synthesis of the membrane (CTL3), myofibrillar assembly (gelsolin) and mitochondrial functionality (ATP synthase).

Intriguingly, in every stage of myogenic differentiation program we found proteins known to be involved in apoptotic process: this suggests a link between mechanisms regulating apoptosis and those controlling differentiation (Fernando et al., 2002). Moreover, a number of highly expressed heat shock proteins (hsp70 kDa protein 5, hsp 70 kDa protein 8, hspl0, hsp90) suggests a close relationship between differentiation and cellular stress (Tarricone et al., 2006).

Therefore, our proteomic data can be viewed as a resource for target follow-up studies centred on one or more biochemical pathways of particular interest.

As a conclusion, this work provides a description of myogenic differentiation program from the morphological and proteomic point of view, addressed to the hypothetical role of each identified protein expressed in a stage-specific manner. It furtherly highlights the mechanisms governing myoblast differentiation.

\section{Acknowledgements}

The authors are grateful to Dr. Michela Mantuano for help with the cell culture. The work was supported by Urbino University.

\section{References}

Arcuri C, Giambanco I, Bianchi R, Donato R. Annexin V, annexin VI, S100Al and S100B in developing and adult avian skeletal muscles.
Neuroscience 2002;109:371-88.

Asefa B, Dermott JM, Kaldis P, Stefanisko K, Garfinkel DJ, Keller JR. p205, a potential tumor suppressor, inhibits cell proliferation via multiple pathways of cell cycle regulation. FEBS Lett 2006;580: 1205-14.

Balogh A, Mege RM, Sobel A. Growth and cell density-dependent expression of stathmin in C2 myoblasts in culture. Exp Cell Res 1996;224:8-15.

Bini L, Sanchez-Campillo M, Santucci A, Magi B, Marzocchi B, Comanducci $\mathrm{M}$ et al. Mapping of Chlamydia trachomatis proteins by immobiline-polyacrylamide two-dimensional electrophoresis: spot identification by $\mathrm{N}$-terminal sequencing and immunoblotting. Electrophoresis 1996;17:185-90.

Blackwood RA, Ernst JD. Characterization of Ca2(+)-dependent phospholipid binding, vesicle aggregation and membrane fusion by annexins. Biochem J 1990;266:195-200.

Bradford MM. A rapid and sensitive method for the quantitation of microgram quantities of protein utilizing the principle of protein-dye binding. Anal Biochem 1976;72:248-54.

Burattini S, Ferri P, Battistelli M, Curci R, Luchetti F, Falcieri E. $\mathrm{C} 2 \mathrm{C} 12$ murine myoblasts as a model of skeletal muscle development: morpho-functional characterization. Eur J Histochem 2004 48:223-33.

Charrasse S, Comunale F, Grumbach Y, Poulat F, Blangy A, GauthierRouviere C. RhoA GTPase regulates M-cadherin activity and myoblast fusion. Mol Biol Cell 2006;17:749-59.

Cooper RN, Tajbakhsh S, Mouly V, Cossu G, Buckingham M, ButlerBrowne GS. In vivo satellite cell activation via Myf5 and MyoD in regenerating mouse skeletal muscle. J Cell Sci 1999;112(Pt 17): 2895-901.

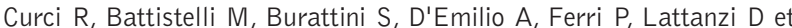
al. Surface and inner cell behaviour along skeletal muscle cell in vitro differentiation. Micron 2008;39:843-51.

Delgado I, Huang X, Jones S, Zhang L, Hatcher R, Gao B et al. Dynamic gene expression during the onset of myoblast differentiation in vitro. Genomics 2003; 82: 109-21.

Fernando P, Kelly JF, Balazsi K, Slack RS, Megeney LA. Caspase 3 activity is required for skeletal muscle differentiation. Proc Nat Acad Sci USA 2002;99:11025-30.

Franco AA, Odom RS, Rando TA. Regulation of antioxidant enzyme gene expression in response to oxidative stress and during differentiation of mouse skeletal muscle. Free Radic Biol Med 1999;27: 1122-32.

Giorgianni F, Desiderio DM, Beranova-Giorgianni S. Proteome analysis using isoelectric focusing in immobilized $\mathrm{pH}$ gradient gels followed by mass spectrometry. Electrophoresis 2003;24:253-59.

Griffiths WJ, Jonsson AP, Liu S, Rai DK, Wang Y. Electrospray and tandem mass spectrometry in biochemistry. Biochem J 2001;355: 545-61.

Grimm J, Sachs M, Britsch S, Di Cesare S, Schwarz-Romond T, Alitalo $\mathrm{K}$ et al. Novel p62dok family members, dok-4 and dok-5, are substrates of the c-Ret receptor tyrosine kinase and mediate neuronal differentiation. J Cell Biol 2001;154:345-54.

Hartman DJ, Hoogenraad NJ, Condron R, Hoj PB. Identification of a mammalian 10-kDa heat shock protein, a mitochondrial chaperonin 10 homologue essential for assisted folding of trimeric ornithine transcarbamoylase in vitro. Proc Natl Acad Sci USA 1992;89: 3394-8.

Hawke TJ, Garry DJ. Myogenic satellite cells: physiology to molecular biology. J Appl Physiol 2001;91:534-51.

Hirano N, Shibasaki F, Sakai R, Tanaka T, Nishida J, Yazaki $Y$ et al. Molecular cloning of the human glucose-regulated protein ERp57/GRP58, a thiol-dependent reductase. Identification of its secretory form and inducible expression by the oncogenic transformation. Eur J Biochem 1995;234:336-42.

Hug C, Jay PY, Reddy I, McNally JG, Bridgman PC, Elson EL et al. Capping protein levels influence actin assembly and cell motility in Dictyostelium. Cell 1995;81:591-600.

Iwasaki K, Hayashi K, Fujioka T, Sobue K. Rho/Rho-associated kinase signal regulates myogenic differentiation via myocardin-related transcription factor-A/Smad-dependent transcription of the Id3 gene. J Biol Chem 2008;283:21230-41.

Keren A, Tamir Y, Bengal E. The p38 MAPK signaling pathway: a major regulator of skeletal muscle development. Mol Cell 


\section{Casadei et al.}

Endocrinol 2006;252:224-30.

Kislinger T, Gramolini A0, Pan Y, Rahman K, MacLennan DH, Emili A. Proteome dynamics during $\mathrm{C} 2 \mathrm{C} 12$ myoblast differentiation. Mol Cell Proteomics 2005; 4:887-901.

Lee WH, Park YM, Kim JI, Park WY, Kim SH, Jang JJ et al. Expression of heat shock protein 70 blocks thymic differentiation of $T$ cells in transgenic mice. Immunology 1998;95:559-65.

Muntoni F, Brown S, Sewry C, Patel K. Muscle development genes: their relevance in neuromuscular disorders. Neuromuscul Disord 2002; 12: 438-46.

Oakley BR, Kirsch DR, Morris NR. A simplified ultrasensitive silver stain for detecting proteins in polyacrylamide gels. Anal Biochem 1980;105:361-3.

Rich BE, Steitz JA. Human acidic ribosomal phosphoproteins $\mathrm{P} 0, \mathrm{Pl}$, and P2: analysis of cDNA clones, in vitro synthesis, and assembly. Mol Cell Biol 1987;7:4065-74.

Runembert I, Queffeulou G, Federici P, Vrtovsnik F, Colucci-Guyon E, Babinet $C$, et al. Vimentin affects localization and activity of sodium-glucose cotransporter SGLT1 in membrane rafts. J Cell Sci 2002;115:713-24

Sestili P, Barbieri E, Martinelli C, Battistelli M, Guescini M, Vallorani $L$ et al. Creatine supplementation prevents the inhibition of myogenic differentiation in oxidatively injured $\mathrm{C} 2 \mathrm{C} 12$ murine myoblasts. Mol Nutr Food Res 2009; in press.

Scholz A, Hinssen $\mathrm{H}$. Biphasic pattern of gelsolin expression and variations in gelsolin-actin interactions during myogenesis. Exp Cell Res
1995; 219:384-91.

Shevchenko A, Wilm M, Vorm 0, Mann M. Mass spectrometric sequencing of proteins silver-stained polyacrylamide gels. Anal Chem 1996; 68: 850-8.

Son YS, Park JH, Kang YK, Park JS, Choi HS, Lim JY et al. Heat shock $70-k D a$ protein 8 isoform 1 is expressed on the surface of human embryonic stem cells and downregulated upon differentiation. Stem Cells 2005; 23: 1502-13.

Tannu NS, Rao VK, Chaudhary RM, Giorgianni F, Saeed AE, Gao Y et al. Comparative proteomes of the proliferating $C(2) C(12)$ myoblasts and fully differentiated myotubes reveal the complexity of the skeletal muscle differentiation program. Mol Cell Proteomics 2004; 3: 1065-82.

Tarricone E, Ghirardello A, Zampieri S, Elisa RM, Doria A, Gorza L. Cell stress response in skeletal muscle myofibers. Ann N Y Acad Sci 2006;1069: 472-6.

Tomczak KK, Marinescu VD, Ramoni MF, Sanoudou D, Montanaro F $\mathrm{Han} \mathrm{M}$ et al. Expression profiling and identification of novel genes involved in myogenic differentiation. Faseb J 2004; 18: 403-5.

Yun BG, Matts RL. Hsp90 functions to balance the phosphorylation state of Akt during $\mathrm{C} 2 \mathrm{C} 12$ myoblast differentiation. Cell Signal 2005; 17:1477-85.

Zhao SH, Nettleton D, Liu W, Fitzsimmons C, Ernst CW, Raney NE et al. Complementary DNA macroarray analyses of differential gene expression in porcine fetal and postnatal muscle. J Anim Sci 2003; 81: 2179-88. 